\title{
A IMPORTÂNCIA DO CONTROLE EXTERNO, EXERCIDO PELO TRIBUNAL DE CONTAS E A PRESTAÇÃO DE CONTAS À SOCIEDADE
}

\author{
Jheffersom Donner da Silva, e-mail: jheffersom.donner@ifam.edu.br \\ Associação Goiana de Administração / Comitê Científico / Goiânia/GO.
}

\section{Resumo:}

O presente artigo científico tem a preocupação básica de examinar a importância do controle externo do Tribunal de Contas para a Administração pública, conceituando o controle externo, e exemplificando as funções dos Tribunais de Contas. Tendo como objetivo destacar a fiscalização exercida pelo Tribunal de Contas, como meio de controle social e instrumentalização da prestação de contas. Optou-se pelo método de pesquisa bibliográfica, considerando as contribuições de vários autores como MAZZA (2012), MEIRELLES (2016), CASTRO (2003), CONSTITUIÇÃO FEDERAL DE 1988, entre outros. Procurou-se enfatizar a importância da prestação de contas a sociedade, e explicar o funcionamento e a importância dos Tribunais de Contas, utilizando-se o conhecimento adquirido a partir da análise teórica de doutrinadores e da legislação constitucional vigente. $\mathrm{O}$ assunto é relevante para a Administração Pública, pois, visa evitar o abuso de poder, a lesão ao patrimônio público, e crimes de improbidade administrativa. Destacou-se, que um dos objetivos do tribunal, através da prestação de contas, é inibir os desvios de verbas públicas,e ainda combater a improbidade administrativa, sendo uma forma de controle externo, baseado na legalidade, moralidade, impessoalidade, publicidade e eficiência dentre outros princípios da Administração Pública.

\section{Palavras-Chave:}

Instrumentalização do controle social, Administração Pública,Prestação de Contas.

\section{Introdução}

O presente objeto deste trabalho é explicar como o controle externo é exercido na Administração Pública, demonstrando como as políticas de físcalização e tomada de contas ajudam no controle social, esclarecendo para a sociedade os gastos e investimentos públicos, tendo em vista uma administração com foco nos resultados, buscando ser eficiente e eficaz, ou seja, gerencial, para alcançar as políticas públicas, direcionada ao bem comum e aos interesses da população, que hoje é visto como um cliente que busca resultados do governo e uma gestão baseada na efetividade.

Para entender melhor o controle externo, vamos ver que o funcionamento da máquina pública gira através de receitas e despesas, ou seja, existe um orçamento público, que detalha 
esses elementos, e que deve ser cumprido, sendo a tomada de contas um meio de sua fiscalização.

Importante ressaltar também que a própria administração possui um sistema de controle interno, derivado do poder de autotutela, assim, a administração pode rever seus próprios atos. Esse órgão interno ao ter ciência de alguma irregularidade interna, deve imediatamente comunicar ao Tribunal de Contas. Frisando que o Tribunal de contas auxilia o Poder Legislativo no exercício do controle externo. Por exemplo, no âmbito da União, o Presidente da República presta contas ao Congresso Nacional, no entanto, tais contas recebem parecer prévio do Tribunal de Contas da União.

Daí deriva a importância dos Tribunais de Contas e o controle, este último existe há muito tempo, pois, a humanidade sempre precisou controlar suas ações para que conseguisse obter melhores resultados, no Brasil foram, por exemplo, criadas as juntas das Fazendas das Capitanias e a Junta da Fazenda do rio de Janeiro, Jurisdicionadas a Portugal, ou seja, Portugal já entrou controlando tudo no Brasil, e no decorrer da história do Brasil pode-se perceber que foram criadas várias formas de controlar a despesa pública e o erário.

Nesta perspectiva, construíram-se indagações que serão solucionadas neste artigo, como por exemplo:

- O que é o controle externo?

- Qual a função dos tribunais de contas da União, dos Estados e dos Municípios?

- Qual a relação entre sociedade e administradores da máquina pública?

- Qual a importância da Administração pública gerencial para o melhor alcance dos desejo e anseios da coletividade?

Quando falamos em administração pública e no bem-estar da coletividade, ou do povo, precisamos usar sérios critérios de avaliação e de controle para mensurar os processos usados, verificar a efetividade, buscando assim respostas, para alcançar melhorias para a sociedade. Daí a importância de investigar o que é feito com o dinheiro público, e se não há desvio de finalidadena máquina pública.

Vários autores conceituam a importância do controle externo, da administração pública, e do Tribunal de Contas para o mais adequado e prudente funcionamento do controle e da prestação de contas dos gestores à sociedade.

Conforme Alexandre Mazza: 
Os tribunais de Contas são importantes auxiliares do Poder Legislativo no controle externo das atuações administrativas são os Tribunais de Contas. Os Tribunais de Contas têm competência para fiscalização de quaisquer entidades públicas ou privadas que utilizem dinheiro público, incluindo as contas do Ministério Público, do Poder Legislativo e do Poder Judiciário. (MAZZA, .2012, p. 621)

Segundo, Hely Lopes Meirelles, em Direito Administrativo Brasileiro:

As atividades dos Tribunais de Contas do Brasil expressam-se fundamentalmente em funções técnicas opinativas, verificadoras, assessoradoras e jurisdicionais administrativas, desempenhadas simetricamente tanto pelo TCU quanto pelos dos Estados-membros, do Distrito Federal e dos Municípios que os tiverem (presentemente, só o Município de São Paulo e o do Rio de Janeiro os têm). (MEIRELLES, 2016, p.844)

Para, Agustinho Vicente Paludo:

No âmbito federal, o controle externo é exercido pelo Congresso Nacional, com o auxílio do Tribunal de Contas da União (art. 71 da CF). Nos estados é exercido pela Assembléia Legislativa, com o auxílio dos Tribunais de Contas Estaduais. No Distrito Federal, é exercido pela Câmara Legislativa, com o auxílio do Tribunal de Contas do Distrito Federal. Nos Municípios, é exercido pela Câmara Municipal, com o auxílio de Tribunais de Contas Estaduais ou Municipais, onde houver. (PALUDO, 2010 , p. 103)

Neste contexto, o objetivo primordial deste estudo é explanar o que é o controle externo do Tribunal de Contas, e qual a relação da prestação de contas a sociedade e qual seu objetivo.

Para alcançar os objetivos propostos, utilizou-se como recurso metodológico, a pesquisa bibliográfica, realizada a partir da análise de materiais já publicados na literatura, como doutrinas, livros, a Constituição Federal, e sumulas, e consultas a informações básicas no site do Tribunal de Contas da União.

As lições desse texto foram fundamentadas nas idéias e concepções de autores como Mazza (2012), Meirelles (2016) e ainda informações coletadas do portal do Tribunal de Conta da União.

\section{Dos Tribunais de Contas}

A sociedade tem cobrado a cada dia mais por seus direitos, assim, é fator preponderante no processo de formação do orçamento público, que se escute quais são as necessidades do povo, portanto, o orçamento é uma ferramenta que tem o objetivo primordial de corrigir distorções administrativas, como também, alterar condições indesejáveis para a sociedade, excluir empecilhos institucionais e assegurar o alcance de planos e das metas que 
se procuram atingir. Já com respeito ao manejo da execução orçamentária, a Constituição Federal de 1988 prenuncia, por força do art. 70, dois tipos de fiscalização sobre o orçamento: o controle interno e o controle externo.

O controle interno é realizado pelos sistemas de Controle Interno de cada Poder. Já o controle externo é realizado pelo Congresso Nacional em âmbito federal, com auxilio do Tribunal de Contas da União; na esfera estadual o controle externo é exercido pela Assembléia Legislativa, com o auxílio do Tribunal de Contas do Estado; e no contexto Municipal o controle externo é exercido pelas Câmaras de Vereadores, sendo que apenas alguns municípios no país, possuem Tribunal de Contas dos Municípios.

Sobre a fiscalização contábil, financeira, orçamentária, operacional e patrimonial da União, observe o que dispõe o artigo 70 da Constituição Federal:

Art. 70. A fiscalização contábil, financeira, orçamentária, operacional e patrimonial da União e das entidades da administração direta e indireta, quanto à legalidade, legitimidade, economicidade, aplicação das subvenções e renúncia de receitas será exercida pelo Congresso Nacional, mediante controle externo, e pelo sistema de controle interno de cada Poder.

Parágrafo único - Prestará contas qualquer pessoa física ou entidade pública que utilize, arrecade, guarde, gerencie ou administre dinheiros, bens e valores públicos ou pelos quais a União responda, ou que, em nome desta, assuma obrigações de natureza pecuniária.

Os chefes do Poder Executivo, que detém o múnus de guardar e aplicar o dinheiro público, e devem prestar contas de sua gestão ao Poder Legislativo, suas contas recebem parecer prévio dos Tribunais de Contas.

Em âmbito federal, podemos definir Tribunal de Contas da União como o órgão que auxilia o Poder Legislativo, ou seja, o Congresso Nacional, composto de 9 (nove) ministros, que, não devem ser considerados magistrados, no entanto gozam das mesmas garantias, prerrogativas, impedimentos, vencimentos e vantagens do Ministro do Superior Tribunal de Justiça (STJ), sendo a esses equiparados. Em âmbito estadual, o órgão que auxilia as Assembléias Legislativas são os Tribunais de Contas Estaduais.

As decisões dos Tribunais de Contas possuem eficácia de título executivo. Ressalta-se, ainda, que de acordo com a súmula vinculante número 3 do Supremo Tribunal Federal, os processos que correm perante o Tribunal de Contas da União é assegurado o contraditório e a ampla defesa. 


\subsection{O Controle Externo}

O controle externo tem como função propícia, resguardar a integridade da administração pública, através da prestação de contas dos gestores públicos, que são responsáveis por gerir os bens e dinheiros públicos. Para Castro (2003, p.128), o controle externo a cargo do Poder Legislativo somente "pode ser exercido em sua plenitude com o auxílio imprescindivel dos Tribunais de Contas respectivos".

Segundo Hely Lopes Meirelles:

O controle externo visa a comprovar a probidade da Administração e a regularidade da guarda e do emprego dos bens, valores e dinheiros públicos, assim como a fiel execução do orçamento. E, por excelência, um controle político de legalidade contábil e financeira, o primeiro aspecto a cargo do Legislativo; o segundo, do Tribunal de Contas. (MEIRELLES, 2016, p.842)

Finalmente, com a Constituição de 1988, o Tribunal de Contas da União teve a sua jurisdição e competência substancialmente ampliadas. Recebeu poderes para, no auxílio ao Congresso Nacional, exercer a fiscalização contábil, financeira, orçamentária, operacional e patrimonial da União e das entidades da administração direta e indireta, quanto à legalidade, à legitimidade e à economicidade e a fiscalização da aplicação das subvenções e da renúncia de receitas. Assim qualquer pessoa física ou jurídica, pública ou privada, que utilize, arrecade, guarde, gerencie ou administre dinheiros, bens e valores públicos ou pelos quais a União responda ou que, em nome desta, assuma obrigações de natureza pecuniária tem o dever de prestar contas ao TCU, quanto aos Estados e os Municípios a Constituição Federal de 1988, define o formato do TCU, as suas atribuições, sua composição, prerrogativas e garantias nos artigos 70 a 74. E determina explicitamente que este formato se aplica também aos Tribunais de Contas no âmbito estadual e municipal, quando houver, conforme artigo 75 da carta magna.

O texto constitucional é repetido nas Constituições Estaduais por simetria, com os apropriados ajustes, pertinentes ao assunto. Cabe destacar os dizeres da Constituição Federal, sobre o Tribunal de Contas da União:

Art. 71. O controle externo, a cargo do Congresso Nacional, será exercido com o auxílio do Tribunal de Contas da União, ao qual compete:

I - apreciar as contas prestadas anualmente pelo Presidente da República, mediante parecer prévio que deverá ser elaborado em sessentadias a contar de seu recebimento; 
II - julgar as contas dos administradores e demais responsáveis por dinheiros, bens e valores públicos da administração direta e indireta, incluídas as fundações e sociedades instituídas e mantidas pelo Poder Público federal, e as contas daqueles que derem causa a perda, extravio ou outra irregularidade de que resulte prejuízo ao erário público;

III - apreciar, para fins de registro, a legalidade dos atos de admissão de pessoal, a qualquer título, na administração direta e indireta, incluídas as fundações instituídas e mantidas pelo Poder Público, excetuadas as nomeações para cargo de provimento em comissão, bem como a das concessões de aposentadorias, reformas e pensões, ressalvadas as melhorias posteriores que não alterem o fundamento legal do ato concessório;

IV - realizar, por iniciativa própria, da Câmara dos Deputados, do Senado Federal, de Comissão técnica ou de inquérito, inspeções e auditorias de natureza contábil, financeira, orçamentária, operacional e patrimonial, nas unidades administrativas dos Poderes Legislativo, Executivo e Judiciário, e demais entidades referidas no inciso II;

V - fiscalizar as contas nacionais das empresas supranacionais de cujo capital social a União participe, de forma direta ou indireta, nos termos do tratado constitutivo; VI - fiscalizar a aplicação de quaisquer recursos repassados pela União mediante convênio, acordo, ajuste ou outros instrumentos congêneres, a Estado, ao Distrito Federal ou a Município;

VII - prestar as informações solicitadas pelo Congresso Nacional, por qualquer de suas Casas, ou por qualquer das respectivas Comissões sobre a fiscalização contábil, financeira, orçamentária operacional e patrimonial e sobre os resultados de auditorias e inspeções realizadas;

VIII - aplicar aos responsáveis, em caso de ilegalidade de despesa ou irregularidade de contas, as sanções previstas em lei, que estabelecerá, entre outras cominasses, multa proporcional ao dano causado ao erário;

IX - assinar prazo para que o órgão ou entidade adote as providências necessárias ao exato cumprimento da lei, se verificada ilegalidade;

Sendo assim é visível também que os administradores devem ter uma relação de prestadores de contas a sociedade, evitando fraudes e desperdícios, e garantindo a correta aplicação dos recursos, buscando sempre observar os princípios da legalidade, impessoalidade, moralidade, publicidade e eficiência, dentre outros princípios também implícitos como o da indisponibilidade dos bens e interesses públicos, e da supremacia do interesse público.

\section{A sociedade e os administradores da máquina pública}

A prestação de contas á sociedade, deve ser da forma mais transparente possível, pois, isso é uma obrigação dos gestores, visto que, o dinheiro é público e do povo, foi recolhido 
deles, observando todos os requisitos e princípios do direito tributário. Assim, a população espera que o melhor seja feito com os valores recolhidos de tributos, e que deverão ser revestidos ou voltarem através de benefícios para a coletividade, visando atender as necessidades básicas exigidas pelo bem comum. Como exemplo, podemos citar a educação, a saúde, a segurança, sendo assim é necessária que haja também uma cobrança das pessoas para com os governantes.

A prestação de contas deverá ser apresentada pelosadministradores, ou seja, os que respondem pelo dinheiro bens e valores públicos da Administração, direta e indireta, incluindotodas as fundações e sociedades instituídas e que são mantidas pelo Poder Público.

O dever de prestar contas é inerente a quem exerce poder. Quem exerce poder não o faz em nome próprio, mas de outrem. Tratando-se de autoridade administrativa, esta exercita poderes em nome da coletividade, que efetivamente os detém como seus. No só prestar contas, função do administrador, não está subsumida a satisfação de sua gestão, que só se exonerará de responsabilidade administrativa e políticoadministrativa com a deliberação, acolhendo-as como regulares. (CASTRO, 2003, p. 13).

A sociedade deve acompanhar o trabalho dos Tribunais de Contas, como meio de controle social, dos gastos e investimentos públicos, feitos por detentores do dinheiro e bens públicos. É importante esse apoio, para que a população conheça os seus representantes, e acompanhem o uso das verbas públicas, e as despesas do governo.

O Tribunal de Contas exerce esse controle social, representando a coletividade, quando julga as contas de gestores, e ainda quando emite pareces, como por exemplo, a emissão de parecer das contas do Presidente da República, feito pelo TCU ao Congresso Nacional. As atividades típicas, detalhadas pela Constituição Federal,são importantes formas de controle.

\subsection{Administração Pública Gerencial}

A Administração pública está em constante transformação, visando atender as necessidades dos seus clientes, que é a população, assim, tem como desafio se adequar às mudanças, ouvindo e atendendo ao povo, voltando-se para o modelo de accountability. Esse modelo projeta a prestação de contas do gestor para além dos limites formais burocráticos, e responsabiliza-os perante a sociedade na salvaguarda dos ativos públicos contra excessos de poder e outros interesses que não sejam o coletivo. Esta administração supõe que o Estado 
seja como uma empresa, e que seus serviços serão prestados da melhor forma possível, e assim funcione principalmente com os objetivos de:

- Eficiência nos serviços e produtos oferecidos;

- Com um alto nível de avaliação e retorno;

- Com Feedeback a sociedade;

- Efetividade e eficácia;

- Estar sempre inovando,em termos de avanços tecnológicos, para conseguir competir de igual com outros países.

Tudo isso pelo bem comum, também pelas mudanças ocorridas no mundo moderno e a globalização, assim a administração pública poderá concorrer com igualdade econômica e social com outros países.

Isso ficou claro quando Pereira disse:

\begin{abstract}
A atual reforma está apoiada na proposta de administração pública gerencial, como uma resposta à grande crise do Estado dos anos 80 e à globalização da economia, dois fenômenos que estão impondo, em todo o mundo, a redefinição das funções do Estado e da sua burocracia. A crise do Estado implicou na necessidade de reformá-lo e reconstruí-lo; a globalização tornou imperativa a tarefa de redefinir suas funções. Antes da integração mundial dos mercados e dos sistemas produtivos, os Estados podiam ter como um de seus objetivos fundamentais proteger as respectivas economias da competição internacional. Depois da globalização, as possibilidades do Estado de continuar a exercer esse papel diminuíram muito. Seu novo papel é o de facilitar para que a economia nacional se torne internacionalmente competitiva. A regulação e a intervenção continuam necessárias, na educação, na saúde, na cultura, no desenvolvimento tecnológico, nos investimentos em infraestrutura - uma intervenção que não apenas compense os desequilíbrios distributivos provocados pelo mercado globalizado, mas principalmente que capacite os agentes econômicos a competir a nível mundial. (PEREIRA 1996, p. 7)
\end{abstract}

Desse modo é visível que com a reforma gerencial, os administradores públicos devem prestar contas e ainda tornar possível o atendimento as necessidades de quem ela representa visando o alcance metas e objetivos antes traçados, observando o que for necessário na base da legalidade e da eficiência, eficácia e efetividade, para o alcance do melhor para o bem comum.

Conforme, já comentado anteriormente, é imprescindível então um controle eficiente e eficaz para fiscalizar as contas, verificar e corrigir erros, e avaliar se o que os governantes tem feito com o erário público está de acordo com o que foi solicitado pelos cidadãos e se está 
havendo o correto uso dos dinheiros e bens públicos, para tentar acabar com a corrupção e com o patrimonialismo que por acaso vierem a persistir no país.

Portanto, se o governante trabalha procurando cumprir seus deveres e obrigações baseados na legalidade, e na eficácia conseguirá alcançar bons resultados que beneficiarão a todos, inclusive ele, que faz parte daquela sociedade.

\section{Conclusão}

Diante do exposto, conclui-se, que é importantíssimaessa função de controle externo, dos Tribunais de Contas e esta prestação de contas a sociedade, e que a interação existente entre o tribunal de contas e os cidadãos por meio desse instrumento é também um controle social, já que assim, pode-se fiscalizar, se os objetivos propostos no orçamento, que foram criados numa parceria com a sociedade, buscando atender suas necessidades estão sendo cumpridos, e se o uso do que é público está sendo bem aplicado.

Ressalta-se, que na esfera federal o controle externo a cargo do Congresso Nacional, será exercido com o apoio do Tribunal de Contas da União e esse deverá apreciar as contas prestadas anualmente pelo Presidente da República, julgar as contas dos administradores e responsáveis pelos dinheiros públicos, apreciar a legalidade dos atos, realizarem inspeções e auditorias: contábil, financeira, orçamentária, operacional e patrimonial nas unidades administrativas dos três poderes e demais entidades, como também, prestar as informações solicitadas pelo Congresso Nacional, aplicar aos responsáveis em caso de ilegalidade de despesa ou de contas, as sanções previstas em lei, dentre algumas outras funções.

Tudo isso dever ser feito com base na legalidade e legitimidade dos atos e também procurando o alcance dos objetivos dos cidadãos, através de uma gestão pública gerencial, que alcance o melhor para a sociedade.

Por fim, cabe ao gestor público prestar contas aos Tribunais de Contas, entregando assim a sociedade os resultados dos seus atos, com transparência e eficiência, zelando e observando pelas necessidades da coletividade, e alcançando assim, êxito no atendimento de seus anseios, sem ferir a legalidade.

\section{REFERÊNCIAS}


CASTRO, Flávio Régis Xavier de Moura e. O novo Tribunal de Contas: visão sistêmica das leis orgânicas dos Tribunais de Contas dos Estados e Municípios do Brasil. Disponível em: $<$ https://www.tce.ba.gov.br/images/artigo_visao_sistemica_leis_organicas.pdf $>$ Acesso em : $17 \mathrm{de}$ jan de 2018 .

CASTRO, José Nilo de Castro. Julgamento das Contas Municipais. 3. ed. rev., atual e ampl. Belo Horizonte: Del Rey, 2003.

BRASIL, Constituição (1988). Constituição da República Federativa do Brasil. 10 ed. São Paulo: Rideel, 2004.

PEREIRA, Luiz Carlos Bresser. Da administração pública burocrática à gerencial. Disponível em: $<$ https://revista.enap.gov.br/index.php/RSP/article/viewFile/702/550.PDF>. Acesso em 20 de dez de 2017.

MEIRELLES, Hely Lopes. Direito administrativo brasileiro. 42 ed. São Paulo: Malheiros,2016.

BRASIL, Supremo Tribunal Federal. Súmula Vinculante n 3. 2007.Disponível em: $<$ http://www.stf.jus.br/portal/jurisprudencia/menuSumario.asp?sumula=1191> Acesso em: 10 de nov de 2017.

PALUDO, Augustinho Vicente. Orçamento público e administração financeira e orçamentária. $1^{\mathrm{a}}$ ed. Rio de Janeiro: Elservier, 2010.

MAZZA, Alexandre. Manual de direito administrativo. $2^{\mathrm{a}}$ ed. São Paulo: Saraiva, 2012. 